OPEN ACCESS

Edited by:

Angelica Merlot,

University of New South Wales,

Australia

Reviewed by:

Camillo Porta,

Policlinico San Matteo Fondazione

(IRCCS), Italy

Jin Wang,

University of Texas MD Anderson

Cancer Center, United States

*Correspondence:

Xiong-Bing Zu

whzuxb@163.com

He-Qun Chen

chqun101@hotmail.com

tThese authors have contributed equally to this work.

Specialty section: This article was submitted to Integrative Physiology, a section of the journal Frontiers in Physiology

Received: 10 January 2018 Accepted: 24 May 2018

Published: 11 June 2018

Citation:

Chen J-B, Zhang M, Cui Y, Liu P-H,

Qi Y-W, Li C, Cheng $X$, Ren W-B,

Li Q-Q, Liu L-F, Chen M-F, Chen H-Q and Zu X-B (2018) Association

Between 12 Polymorphisms of VEGF/Hypoxia/Angiogenesis Pathway

Genes and Risk of Urogenital Carcinomas: A Meta-Analysis Based

on Case-Control Studies.

Front. Physiol. 9:715.

doi: 10.3389/fphys.2018.00715

\section{Association Between 12 Polymorphisms of VEGF/Hypoxia/Angiogenesis Pathway Genes and Risk of Urogenital Carcinomas: A Meta-Analysis Based on Case-Control Studies}

\author{
Jin-Bo Chen ${ }^{1 \dagger}$, Meng Zhang ${ }^{2 \dagger}$, Yu Cui ${ }^{1}$, Pei-Hua Liu ${ }^{1}$, Yan-Wei Qi $^{3}$, Chao $\mathrm{Li}^{1}, \mathrm{Xu}$ Cheng ${ }^{1}$ \\ Wen-Biao Ren ${ }^{1}$, Qia-Qia Li ${ }^{1}$, Long-Fei Liu ${ }^{1}$, Min-Feng Chen ${ }^{1}$, He-Qun Chen ${ }^{1 *}$ and \\ Xiong-Bing $\mathrm{Zu}^{1 *}$ \\ ${ }^{1}$ Department of Urology, Xiangya Hospital, Central South University, Changsha, China, ${ }^{2}$ Department of Urology, The First \\ Affiliated Hospital of Anhui Medical University, Hefei, China, ${ }^{3}$ Beijing Genomics Institute, Shenzhen, China
}

Objective: Previous studies indicated potential associations between polymorphisms in genes of VEGF/hypoxia/angiogenesis pathway and risk of urogenital carcinomas However, the results were controversial and inconclusive. Here, we conducted an in-depth meta-analysis to investigate the precise associations between polymorphisms in VEGF/hypoxia/angiogenesis related genes and risk of urogenital carcinomas.

Methods: We searched PubMed, Web of Science, EMBASE, and Cochrane Library to identify all eligible publications. Pooled odds ratios (ORs) corresponding with the 95\% confidence intervals (Cls) were calculated to evaluate their associations. Subgroup analysis was conducted to further ascertain such relationship and investigate sources of heterogeneity.

Results: In the end, a total of 96 case-control studies fulfilled the inclusion criteria were enrolled for 12 polymorphisms in 4 VEGF/hypoxia/angiogenesis related genes. The pooled results showed eNOS-rs2070744 polymorphism conferred a significantly increased overall risk of urogenital carcinomas in allele, homozygote, and recessive models, respectively. In addition, eNOS-Intron 4a/b VNTR polymorphism was identified related to an increased risk of urogenital carcinomas in recessive model. And VEGF-rs699947 polymorphism was also identified an increased risk of renal cell carcinoma (RCC) in allelic, heterozygote, dominant, homozygote, and recessive models.

Conclusion: To conclude, eNOS-rs2070744 and eNOS-Intron 4a/b VNTR polymorphisms are risk factors for urogenital carcinomas. VEGF-rs699947 polymorphism was also identified as an increased risk factor for renal carcinoma.

Keywords: VEGF/hypoxia/angiogenesis, polymorphism, urogenital carcinomas, susceptibility, meta-analysis 


\section{INTRODUCTION}

Urogenital carcinomas, mainly including renal cell carcinoma (RCC), bladder carcinoma (BCa), and prostate carcinoma ( $\mathrm{PCa}$ ), are common malignancies among human neoplasms, with increasing morbidity worldwide in the last 2 decades (Dy et al., 2017). Based on the latest statistics in 2017, estimated incident of urogenital carcinomas accounts for about $20 \%$ of all tumors in the United States. Among them, PCa ranks the highest in man with 161,360 estimated new cases in 2017 (Siegel et al., 2017). In addition to life style and occupational exposure, numerous studies indicated genetic factors such as single nucleotide polymorphisms (SNPs) may be associated with urogenital carcinomas susceptibility (Sun et al., 2008; Stadler et al., 2010).

Angiogenesis, which is the process of new blood vessels formation from original pre-existing vessels, plays a critical role in tumor initiation and development (Nicholson and Theodorescu, 2004). The vascular endothelial growth factor (VEGF) gene is highly polymorphic and several functional SNPs in the VEGF gene alter the expression of the VEGF protein, thereby affecting tumor growth and progression (Ruggiero et al., 2011). The hypoxia-inducible factor- 1 alpha (HIF1 $\alpha$ ) gene is an important transcription factor in cells which regulates cellular responses, adaption, and survival under low oxygen condition in physiological and pathological processes (Li et al., 2013). Several studies demonstrated HIF1 $\alpha$-rs11549465 polymorphism contributed to increase the risk of prostate cancer (Orr-Urtreger et al., 2007; Foley et al., 2009). Endothelial nitric oxide synthase (eNOS) is a central mediator of several endothelium growth stimulators, such as VEGF (Duda et al., 2004; Zhao et al., 2014). Polymorphisms of the eNOS gene plays a vital role in the angiogenesis pathway and have also been found to have functional and clinical significance in malignancies (Haque et al., 2015). HRAS (Harvey rat sarcoma viral oncogene homolog) gene has been uncovered as one of the major factors in the initiation and progression of human malignancies (Zhang et al., 2008). HRAS SNP was also noted to be associated with many cancer susceptibilities.

Clarifying of the role of VEGF/hypoxia/angiogenesis gene polymorphisms in the influence of cancer may improve our knowledge of tumor angiogenesis and benefit risk stratification, disease detection, and prognosis prediction. As mentioned above, many studies have conducted investigations to clarify the associations between these polymorphisms and the risk of urogenital carcinomas, however, these results are controversial and inconsistent. In the current study, we retrieved published data and performed a comprehensive metaanalysis to systematically investigate the association between polymorphisms in VEGF/hypoxia/angiogenesis pathway genes and the risk of urogenital carcinomas.

\section{MATERIALS AND METHODS}

\section{Acquisition of the VEGF/Hypoxia/ Angiogenesis Pathway Gene Set}

The gene set of VEGF/hypoxia/angiogenesis pathway was referenced from the Kyoto Encyclopedia of Genes and Genomes
(KEGG) website. The VEGF/hypoxia/angiogenesis pathway gene set could be extracted via following URL link (http:// software.broadinstitute.org/gsea/msigdb/geneset_page.jsp? geneSetName=BIOCARTA_VEGF_PATHWAY\&keywords $=$ angiogenesis). The gene set was originally provided via the KEGG signaling database, and encompassed the following 29 genes: ARNT, EIF1, EIF1AX, EIF2B1, EIF2B2, EIF2B3, EIF2B4, EIF2B5, EIF2S1, EIF2S2, EIF2S3, ELAVL1, FLT1, FLT4, HIF1A, HRAS, KDR, eNOS, PIK3CA, PIK3CG, PIK3R1, PLCG1, PRKCA, PRKCB, PTK2, PXN, SHC1, VEGF, and VHL.

\section{Literature Search Strategy}

We performed a literature search from PubMed, Web of Science, EMBASE, and Cochrane Central Search Library according to the PRISMA guidelines (Shamseer et al., 2015) (last research update: July 20, 2017). The search terms were as follows: (gene OR synset) AND (polymorphism OR mutation OR variation OR SNP OR genotype) AND (carcinoma OR cancer OR neoplasm OR adenocarcinoma OR tumor OR malignancy) (Supplementary Table 1). The language of enrolled studies was restricted to English. Also, we identified additional articles by screening the references of enrolled articles and reviews.

\section{Inclusion and Exclusion Criteria}

Studies fitting the following inclusion criteria were enrolled: (1) articles has shown the association between polymorphisms in genes of VEGF/hypoxia/angiogenesis pathway and risk of urogenital carcinomas; (2) case-control studies; (3) publications with sufficient genotype data to assess odds ratios (ORs) and 95\% confidence intervals (CIs). The exclusion criteria were as follows: (1) case-only studies without a control group, case reports, conference abstracts or reviews; (2) studies without raw data for the genotype; (3) studies with overlapping data.

\section{Data Extraction}

Two authors (JBC and MZ) individually extracted eligible data from each publication based on the inclusion and exclusion criteria. If there is a discrepancy, we reached agreement after discussing with a third author (XBZ). Information collected as follows: first author name, publication year, ethnicity, genotyping methods, source of controls including populationbased (PB) or hospital-based (HB), Hardy-Weinberg equilibrium (HWE), cancer type, number of cases, and controls in the VEGF/hypoxia/angiogenesis genotypes. The Newcastle-Ottawa Scale (NOS) was used for assessing the quality of studies. Highquality study required score 7 to 9 , and a score less than 7 defined as a low-quality study (Supplementary Table 2).

\section{Linkage Disequilibrium (LD) Analysis Across Populations}

The 1,000 genomes Project database (https://www.ncbi.nlm.nih. gov/variation/tools/1000genomes/) was used to extract the LD data, which comprising the polymorphisms in VEGF, HIF-1 $\alpha$ and eNOS evaluated in the present study. Briefly, populations enrolled in the project including JPT (Japanese in Tokyo, Japan), 
YRI (Yoruba in Ibadan, Nigeria), CEU (Utah residents with Northern and Western European ancestry from the CEPH collection), and CHB (Han Chinese in Beijing, China). The LD was assessed by $r^{2}$ statistics in these populations using Haploview software.

\section{Statistical Analysis}

The association between polymorphisms in four VEGF/hypoxia/angiogenesis pathway genes and the urogenital carcinomas susceptibility were evaluated using summary ORs and the corresponding 95\%CIs. We used allelic (B vs. A), recessive ( $\mathrm{BB}$ vs. $\mathrm{BA}+\mathrm{AA})$, dominant $(\mathrm{BA}+\mathrm{BB}$ vs. $\mathrm{AA})$, homozygous (BB vs. AA), and heterozygous (BA vs. AA) models to analyze each variable (A indicate wild allele and $B$ indicate mutated allele). Q-statistic as well as $I^{2}$ were used to evaluate the heterogeneity within the studies (Higgins et al., 2003). Heterogeneity was considered significant when the $P$-value $<$ 0.1 . If there was no heterogeneity found, a fixed effect model was applied. Otherwise, the random-effect model was used to calculate pooled ORs. The significance of overall ORs was determined by Z-test. Subgroup analyses were performed based on different ethnicity, cancer type, HWE, and the source of control. Sensitivity analysis was conducted to assess the results stability by omitting one study each time. Publication bias was analyzed by Begg's funnel plot and Egger's test (Begg and Mazumdar, 1994; Egger et al., 1997). All analyses were performed using STATA 12.0 statistical software (Stata Corpotation, College Station, TX, USA).

\section{RESULTS}

\section{Main Characteristics of the Eligible Studies}

According to the inclusion and exclusion criteria, only 12 polymorphisms in four genes of VEGF/hypoxia/angiogenesis pathway were identified (VEGF-rs10434, VEGF-rs1570360, VEGF-rs2010963, VEGF-rs3025039, VEGF-rs699947, VEGF-rs833061, HIF1a-rs11549465, HIF1a-rs11549467, eNOS-rs1799983, eNOS-rs2070744, eNOS-Intron 4a/b VNTR, and HRAS-rs12628). Details of the enrolled studies were listed in Table 1 (Clifford et al., 2001; Abe et al., 2002; McCarron et al., 2002; Medeiros et al., 2002; Johne et al., 2003; Lin et al., 2003; Sanyal et al., 2004; Chau et al., 2005; Kim et al., 2005; Marangoni et al., 2006; Sfar et al., 2006; Fukuda et al., 2007; Garcia-Closas et al., 2007; Li et al., 2007, 2012; Orr-Urtreger et al., 2007; Jacobs et al., 2008; Nadaoka et al., 2008; Onen et al., 2008; Foley et al., 2009; Lee et al., 2009; Morris et al., 2009; Ricketts et al., 2009; Bruyère et al., 2010; VanCleave et al., 2010; Ajaz et al., 2011; Ryk et al., 2011; Sanli et al., 2011; Amasyali et al., 2012; Henríquez-Hernández et al., 2012; Qin et al., 2012, 2014; Traczyk et al., 2012; Brankovic et al., 2013; Ianni et al., 2013; Jaiswal et al., 2013; Martinez-Fierro et al., 2013; Pandith et al., 2013; Sáenz-López et al., 2013; Safarinejad et al., 2013; Verim et al., 2013; Wang et al., 2013; Ziaei et al., 2013; Fraga et al., 2014; Yang et al., 2014; Lu et al., 2015; Polat et al., 2015; Shen et al., 2015; Xian et al., 2015; Ceylan et al., 2016; Diler and Oden, 2016). The study selection processes were presented in Figure 1.
For polymorphisms in VEGF gene (VEGF-rs10434, VEGFrs1570360, VEGF-rs2010963, VEGF-rs3025039, VEGF-rs699947, VEGF-rs833061), a total of 49 case-control studies with 8,070 cases and 10,024 controls have met the inclusion criteria. Specifically, there are 918 cases and 1,330 controls in VEGFrs10434, 3,522 cases and 3,167 controls in VEGF-rs 1570360 , 3,106 cases and 4,152 controls in VEGF-rs2010963, 3,582 cases and 4,890 controls in VEGF-rs3025039, 3,252 cases and 4,432 controls in VEGF-rs699947, 2,533 cases and 3,550 controls in VEGF-rs833061, respectively. Twenty-two studies of them were performed in Caucasians, 25 studies in Asians, and others were in mixed ethnic groups (including at least one race). Controls of 35 studies were hospital-based (H-B) and 13 studies were population-based (P-B), only one study didn't show whether it was $\mathrm{H}-\mathrm{B}$ or $\mathrm{P}-\mathrm{B}$. Additionally, the distributions of polymorphisms in VEGF for control groups were consistent with HWE, except for these studies listed here (Lin et al., 2003; Garcia-Closas et al., 2007; Onen et al., 2008; Ianni et al., 2013; Lu et al., 2015; Shen et al., 2015; Xian et al., 2015).

For HIF1 $\alpha$-rs11549465 and rs11549467 polymorphisms, 19 eligible studies comprising 6,064 cases and 6,784 controls were enrolled. There are 5789 cases and 6,360 controls in HIF1 $\alpha$ rs $11549465,3,336$ cases and 4,013 controls in HIF1 $\alpha$-rs 11549467 , respectively. Of them, eight studies were performed on subjects in Caucasians, six in Asians and the other five were in mixed ethnic groups. Moreover, nine studies were $\mathrm{H}-\mathrm{B}$, eight were $\mathrm{P}-\mathrm{B}$ and the other two did not show H-B or P-B. There were several studies not consistent with HWE (Clifford et al., 2001; Chau et al., 2005; Jacobs et al., 2008).

For polymorphisms in eNOS gene (eNOS-rs1799983, eNOSrs2070744, and eNOS-Intron 4a/b VNTR), 24 case-control studies with 4,286 cases and 5,009 controls were included in the current work. Specifically, there are 3,777 cases and 4,429 controls in eNOS-rs1799983, 813 cases, and 854 controls in eNOS-rs2070744, 709 cases and 1,111 controls in eNOS-Intron 4a/b VNTR, respectively. Of them, 23 studies were performed in Caucasian, 1 was in mixed ethnic groups. In addition, among these studies, 13 were $\mathrm{H}-\mathrm{B}$, and 11 were $\mathrm{P}-\mathrm{B}$. All the studies were consistent with HWE. While for HRAS-rs12628 polymorphism, finally, 4 eligible case-control studies comprising 886 cases and 747 controls were included. Of them, 3 studies were performed in Caucasian, 1 in Asian. Of these studies, 2 were $\mathrm{H}-\mathrm{B}$, and 2 were PB. Two studies were not consistent with HWE (Johne et al., 2003; Sanyal et al., 2004).

\section{Quantitative Synthesis}

Table 2 and Supplementary Table 3 listed the main results of current meta-analysis work of polymorphisms in VEGF/hypoxia/angiogenesis pathway genes and risk of urogenital carcinomas.

\section{eNOS-rs2070744}

The pooled results of five included studies had shown eNOSrs2070744 polymorphism conferred a significantly higher overall risk to urogenital carcinomas in allele, homozygote and recessive models ( $\mathrm{B}$ vs. $\mathrm{A}: \mathrm{OR}=1.379,95 \% \mathrm{CI}=1.187-1.602$, 
TABLE 1 | Detail characteristics of enrolled studies.

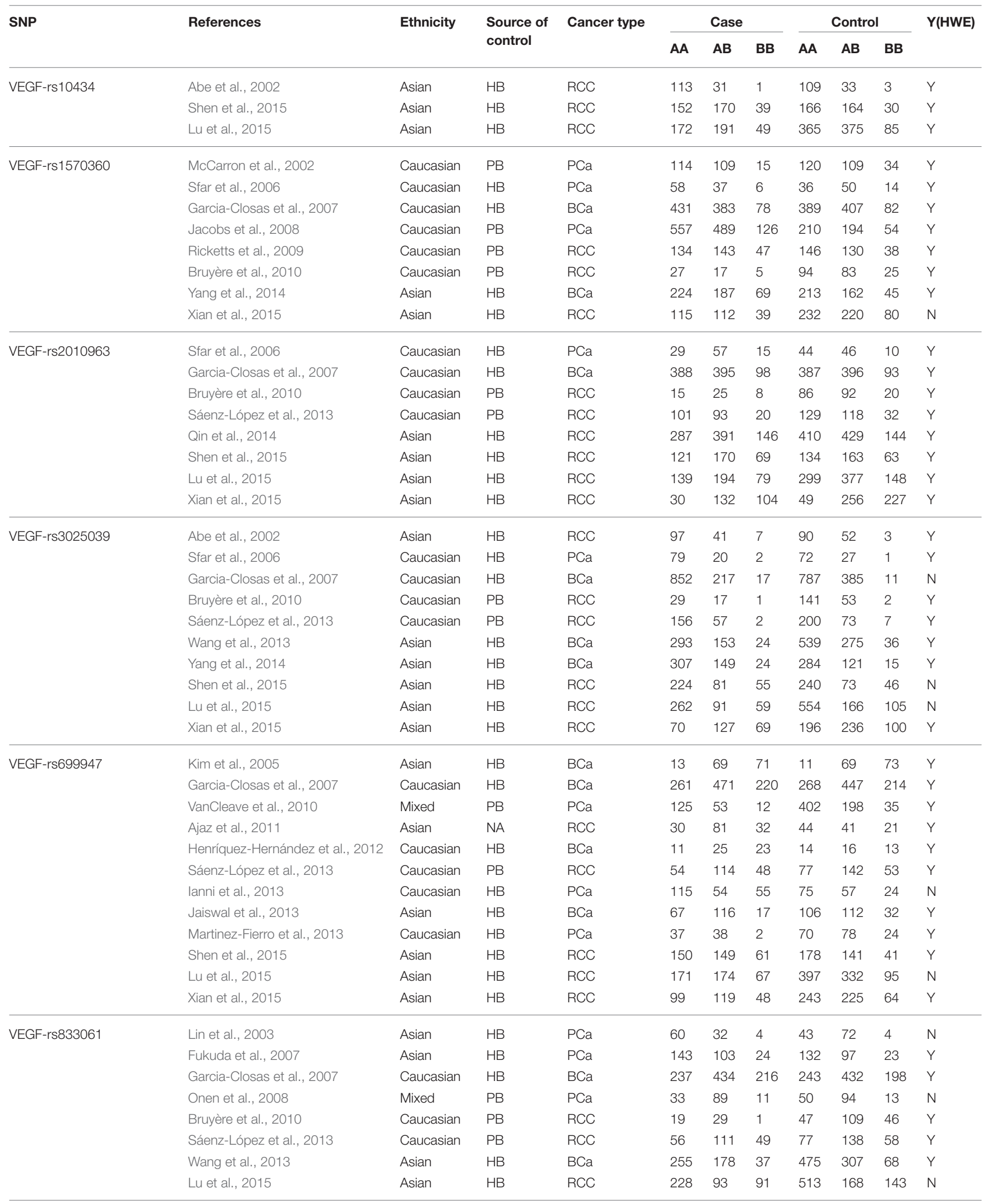


TABLE 1 | Continued

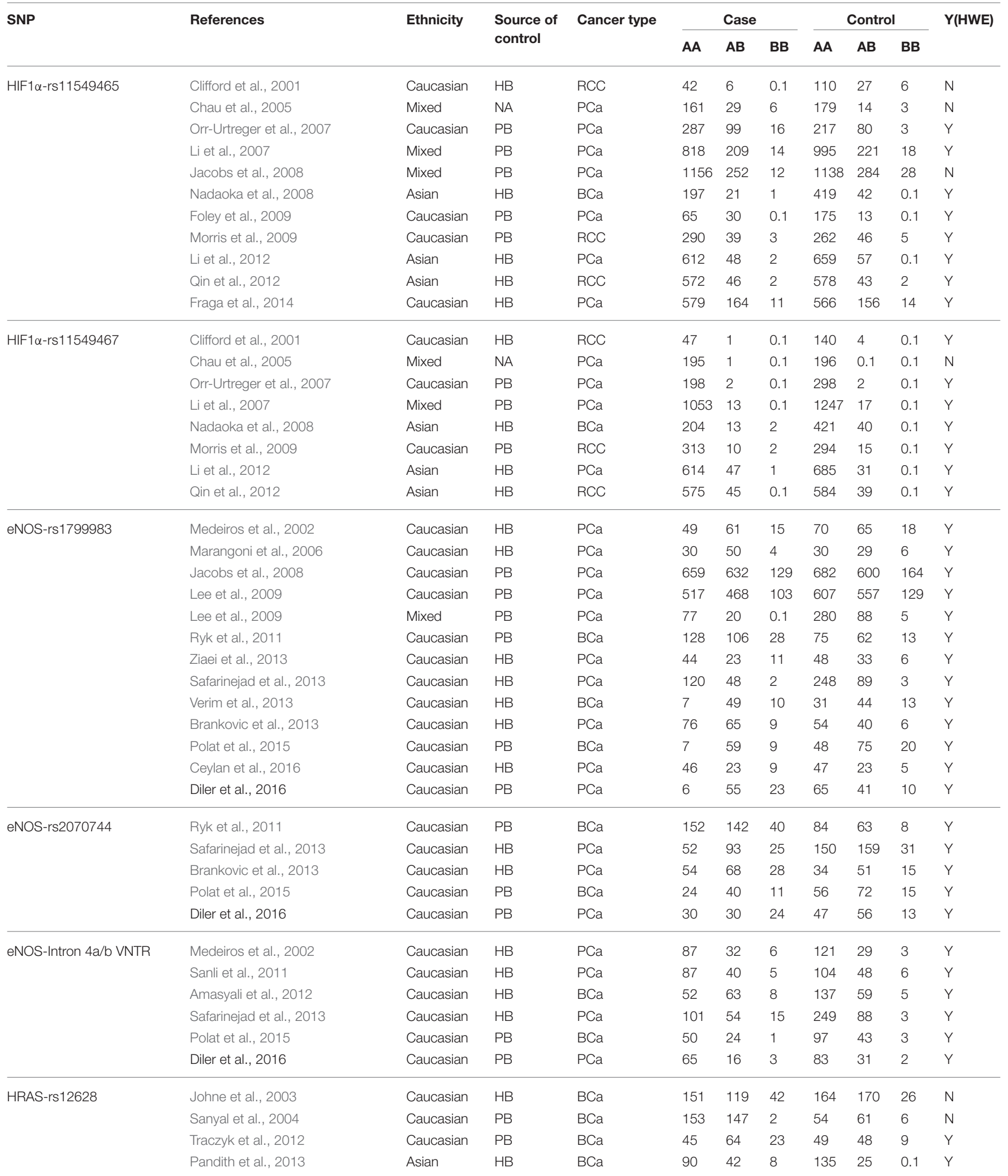

SNP, single nucleotide polymorphism; HB, hospital-based; PB: population-based; RCC, renal cell carcinoma; PCa, prostate cancer; BCa, bladder cancer; HWE, Hardy Weinberg equilibrium; $Y$, controls conformed to HWE; N, controls were not conformed to HWE; Mixed, more than two ethnicities. 
TABLE 2 | Representative results of meta-analysis for polymorphisms in VEGF/ Hypoxia/Angiogenesis genes and risk of Urogenital Carcinomas.

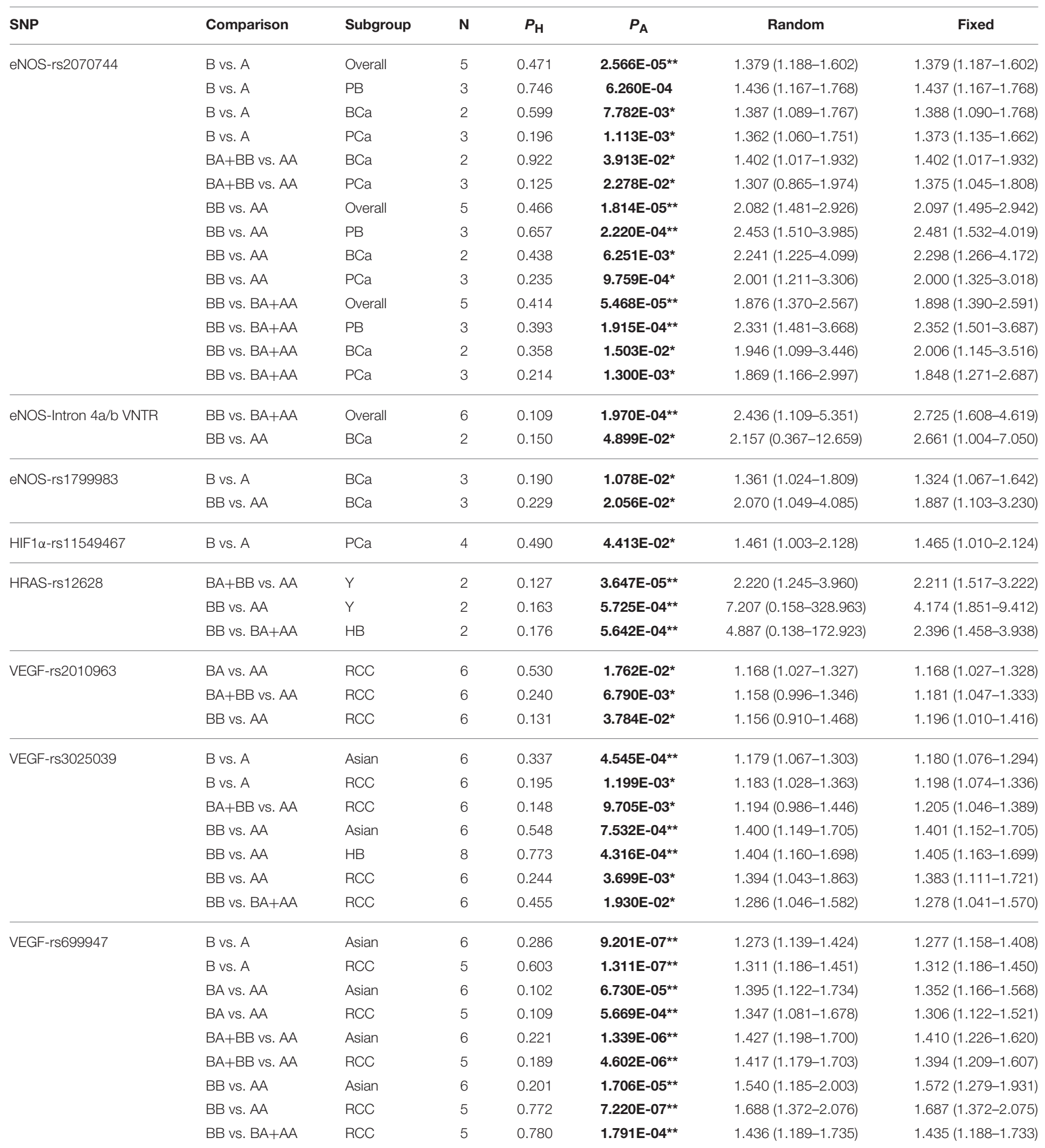

SNP, single nucleotide polymorphism; $P_{H}, P$ value of $Q$ test for heterogeneity test; $P_{A}, P<0.05$ was considered as statistically significant (bold font mark ${ }^{*}$ ) for cancer type subgroup analysis. And multiple testing $P$ value according to Bonferroni correction $[P<0.05 /(12$ polymorphisms $\times 5$ models)] was considered as statistically significant (bold font mark $)$; PCa, prostate cancer; RCC, renal cell carcinoma; BCa, bladder cancer; $H B$, hospital based; PB, population based; HWE, Hardy Weinberg equilibrium. Heterogeneity was considered significant when the P-value < 0.1. A fixed effects model (Der-Simonian Laird) was used if there was no significant heterogeneity; otherwise, a random effects model (Der-Simonian Laird) was used. 


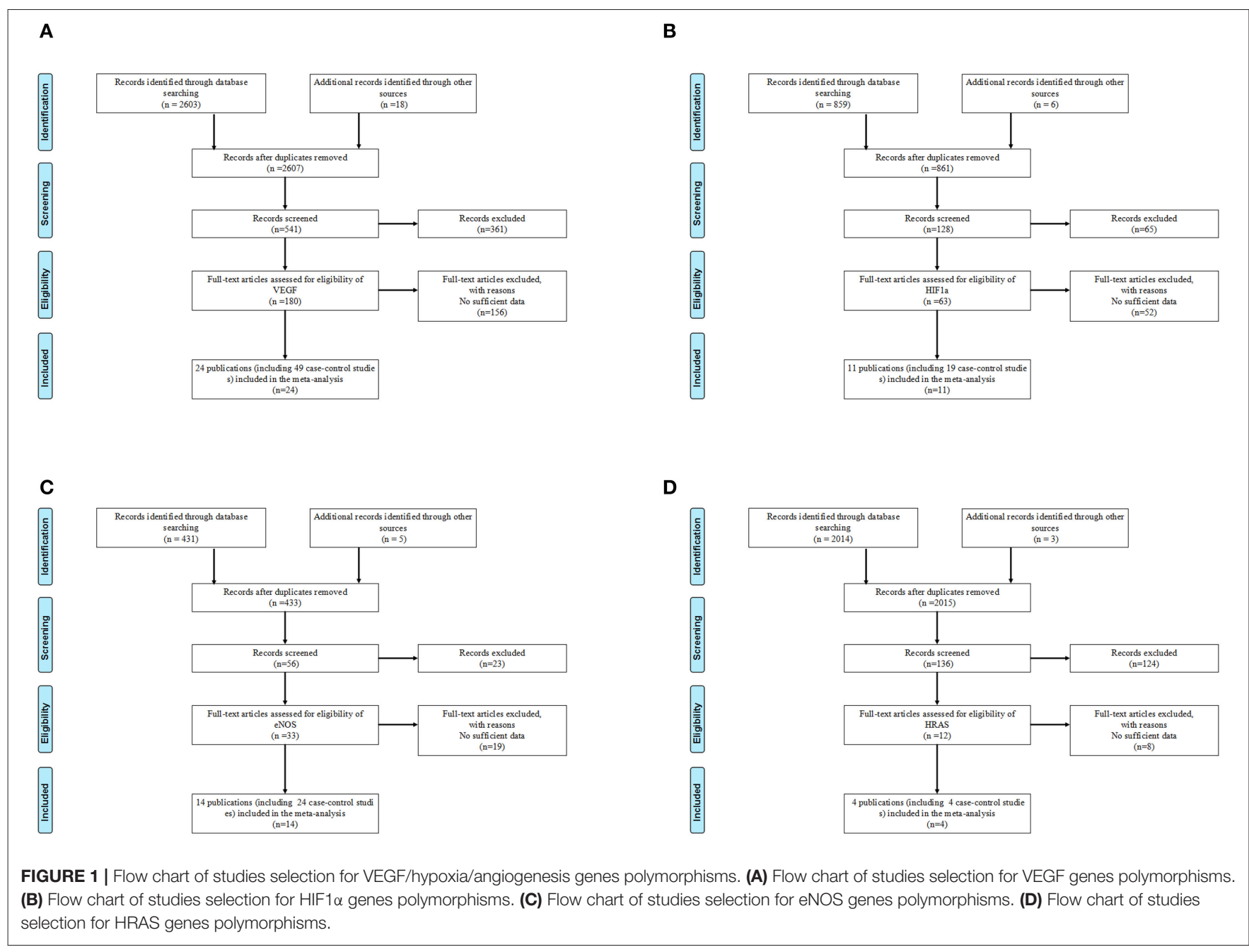

$P_{A}=2.566 \mathrm{E}-05 ; \mathrm{BB}$ vs. $\mathrm{AA}: \mathrm{OR}=2.097,95 \% \mathrm{CI}=1.495-$ 2.942, $P_{A}=1.814 \mathrm{E}-05$ and $\mathrm{BB}$ vs. $\mathrm{BA}+\mathrm{AA}: \mathrm{OR}=1.898$, $\left.95 \% \mathrm{CI}=1.390-2.591, P_{A}=5.468 \mathrm{E}-05\right)$, respectively. In the stratification analysis by source of control, an increased risk of urogenital neoplasms was also identified for P-B groups in allele, homozygote, and recessive models (B vs. A: $O R=1.437$, $95 \% \mathrm{CI}=1.167-1.768, P_{A}=6.260 \mathrm{E}-04$; $\mathrm{BB}$ vs. $\mathrm{AA}: O R=2.481$, $95 \% \mathrm{CI}=1.532-4.019, P_{A}=2.220 \mathrm{E}-04$ and $\mathrm{BB}$ vs. $\mathrm{BA}+\mathrm{AA}$ : $\left.O R=2.352,95 \% \mathrm{CI}=1.501-3.687, P_{A}=1.915 \mathrm{E}-04\right)$. Moreover, when the stratification analysis conducted by cancer type $\left(P_{A}\right.$ value $<0.05$, without Bonferroni correction), we also identified an increased risk of $\mathrm{BCa}$ in allelic, dominant, homozygote and recessive models ( $\mathrm{B}$ vs. $\mathrm{A}: \mathrm{OR}=1.388,95 \% \mathrm{CI}=1.090-1.768$, $P_{A}=7.782 \mathrm{E}-03$; $\mathrm{BA}+\mathrm{BB}$ vs. $\mathrm{AA}: \mathrm{OR}=1.402,95 \% \mathrm{CI}=1.017-$ $1.932, P_{A}=3.913 \mathrm{E}-02$; $\mathrm{BB}$ vs. $\mathrm{AA}: \mathrm{OR}=2.298,95 \% \mathrm{CI}=1.266-$ 4.172, $P_{A}=6.251 \mathrm{E}-03$ and $\mathrm{BB}$ vs. $\mathrm{BA}+\mathrm{AA}: \mathrm{OR}=2.006,95 \% \mathrm{CI}$ $\left.=1.145-3.516, P_{A}=1.503 \mathrm{E}-02\right)$. An increased risk of $\mathrm{PCa}$ in allelic, dominant, homozygote, and recessive models (B vs. A: $O R=1.373,95 \% \mathrm{CI}=1.135-1.662, P_{A}=1.113 \mathrm{E}-03 ; \mathrm{BA}+\mathrm{BB}$ vs. $\mathrm{AA}: \mathrm{OR}=1.375,95 \% \mathrm{CI}=1.045-1.808, P_{A}=2.278 \mathrm{E}-02$;
$\mathrm{BB}$ vs. $\mathrm{AA}: \mathrm{OR}=2.000,95 \% \mathrm{CI}=1.325-3.018, P_{A}=9.759 \mathrm{E}-04$ and $\mathrm{BB}$ vs. $\mathrm{BA}+\mathrm{AA}: \mathrm{OR}=1.848,95 \% \mathrm{CI}=1.271-2.687, P_{A}=$ 1.300E-03).

\section{eNOS-Intron $4 a / b$ VNTR}

For eNOS-Intron 4a/b VNTR polymorphism, a total of six eligible case-control studies were included. The final analysis has shown that eNOS-Intron $4 \mathrm{a} / \mathrm{b}$ VNTR polymorphism was related to an increased risk of urogenital neoplasms in recessive model (BB vs. $\mathrm{BA}+\mathrm{AA}: \mathrm{OR}=2.725,95 \% \mathrm{CI}=1.608-4.619, P_{\mathrm{A}}$ $=1.970 \mathrm{E}-04)$. Subgroups analysis $\left(P_{A}\right.$ value without Bonferroni correction) identified an increased risk of $\mathrm{BCa}$ in homozygote models (BB vs. AA: $O R=2.661,95 \% \mathrm{CI}=1.004-7.050, P_{A}=$ 4.899E-02).

\section{eNOS-rs1799983}

Overall, there was no significant association between eNOSrs1799983 polymorphism and the risk of urogenital neoplasms. However, subgroups analysis by cancer type revealed an increased risk of $\mathrm{BCa}$ in allelic and heterozygote models (B vs. A: 


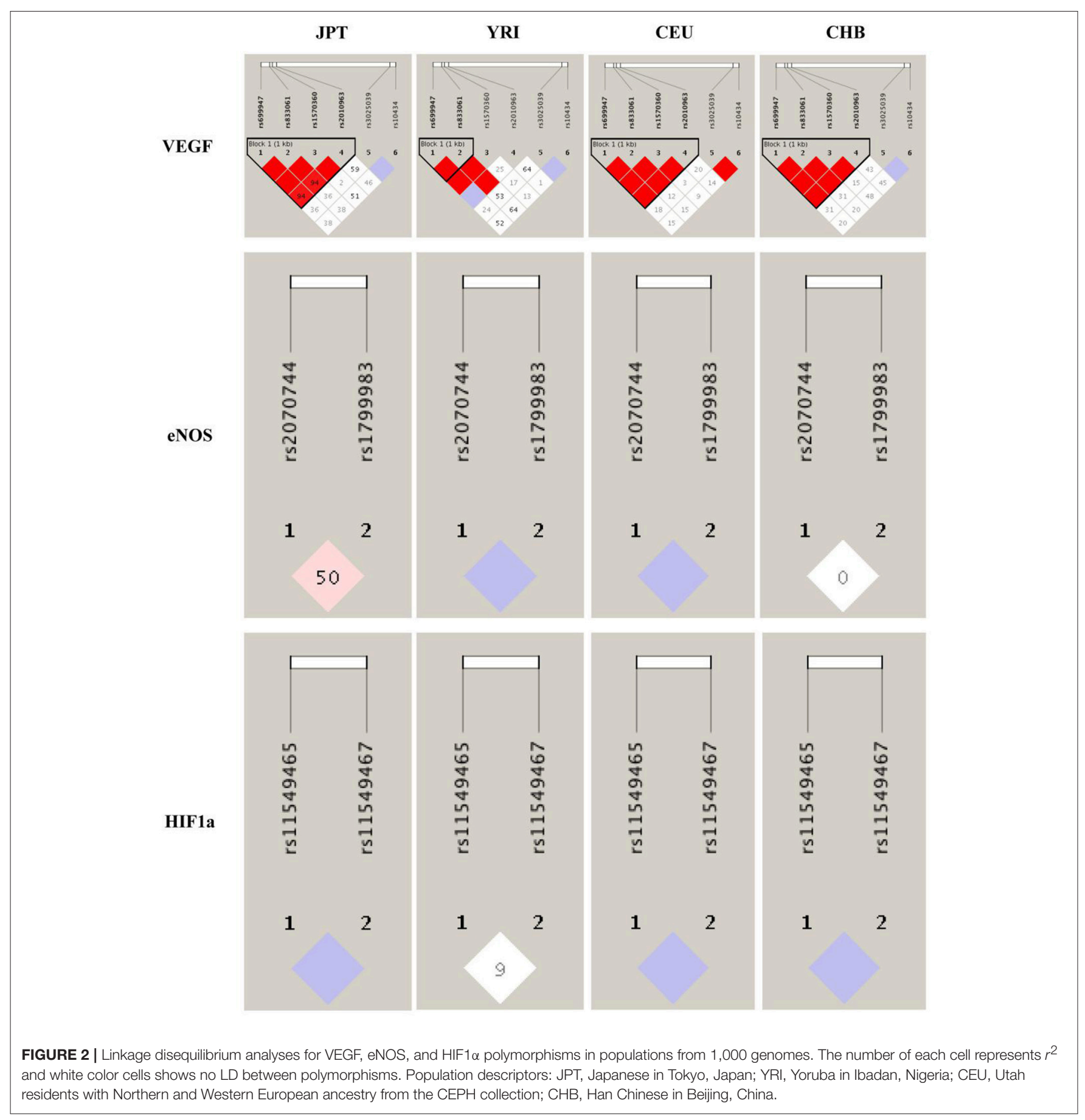

$O R=1.324,95 \% \mathrm{CI}=1.067-1.642, P_{\mathrm{A}}=1.078 \mathrm{E}-02 ; \mathrm{BB}$ vs. $\mathrm{AA}:$ $\left.O R=1.887,95 \% \mathrm{CI}=1.103-3.230, P_{\mathrm{A}}=2.056 \mathrm{E}-02\right)\left(P_{A}\right.$ value without Bonferroni correction).

\section{HIF1a-rs11549467}

Overall, there was no significant association between HIF1ars11549467 polymorphism and the risk of urogenital neoplasms. Subgroups analysis by cancer type revealed an increased risk of PCa in allelic and heterozygote models (B vs. A: $O R=$ $\left.1.465,95 \% \mathrm{CI}=1.010-2.124, P_{\mathrm{A}}=4.413 \mathrm{E}-02\right)\left(P_{A}\right.$ value without Bonferroni correction).

\section{HRAS-rs12628}

No significant association was uncovered for the association between HRAS-rs12628 polymorphism and urogenital carcinomas risk. However, when conducting the stratification analysis by HWE status, we identified an increased risk of urogenital carcinomas (all are BCa studies) in dominant and 
homozygote model for HWE (Y) groups (BB + BA vs. AA: $O R$ $=2.211,95 \% \mathrm{CI}=1.517-3.222, P_{A}=3.647 \mathrm{E}-05 ; \mathrm{BB}$ vs. $\mathrm{AA}: O R$ $\left.=4.174,95 \% \mathrm{CI}=1.851-9.412, P_{A}=5.725 \mathrm{E}-04\right)$. Moreover, in the stratification analysis by source of control, an increased risk of urogenital carcinomas for $\mathrm{H}-\mathrm{B}$ groups was also found (BB vs. $\left.\mathrm{BA}+\mathrm{AA}: \mathrm{OR}=2.396,95 \% \mathrm{CI}=1.458-3.938, P_{A}=5.642 \mathrm{E}-04\right)$.

\section{VEGF-rs2010963}

Overall, there was no significant association between eNOSrs1799983 polymorphism and the risk of urogenital neoplasms. Nevertheless, subgroups analysis by cancer type revealed an increased risk of RCC in heterozygote, dominant, and homozygote models (BA vs. AA: $O R=1.168,95 \% \mathrm{CI}=1.027-$ $1.328, P_{A}=1.762 \mathrm{E}-02$; $\mathrm{BA}+\mathrm{BB}$ vs. $\mathrm{AA}: \mathrm{OR}=1.181,95 \% \mathrm{CI}=$ $1.047-1.333, P_{A}=6.790 \mathrm{E}-03$; $\mathrm{BB}$ vs. $\mathrm{AA}: \mathrm{OR}=1.196,95 \% \mathrm{CI}$ $\left.=1.010-1.416, P_{A}=3.784 \mathrm{E}-02\right)\left(P_{A}\right.$ value without Bonferroni correction).

\section{VEGF-rs3025039}

No significant association was found between VEGF-rs3025039 polymorphism and the risk of urogenital carcinomas. Nevertheless, subgroup analysis by ethnicity showed an increased risk of urogenital carcinomas in allelic and homozygote model for Asian population (B vs. A: $O R=1.180,95 \% \mathrm{CI}=1.076-1.294$, $P_{A}=4.545 \mathrm{E}-04 ; \mathrm{BB}$ vs. $\mathrm{AA}: \mathrm{OR}=1.401,95 \% \mathrm{CI}=1.152-1.705$, $\left.P_{A}=7.532 \mathrm{E}-04\right)$. Moreover, in the stratification analysis by source of control, an increased risk of urogenital carcinomas for $\mathrm{H}-\mathrm{B}$ groups was also found ( $\mathrm{BB}$ vs. $\mathrm{AA}: \mathrm{OR}=1.405,95 \% \mathrm{CI}=$ $\left.1.163-1.699, P_{A}=4.316 \mathrm{E}-04\right)$. Subgroups analysis by cancer type $\left(P_{A}\right.$ value without Bonferroni correction) revealed an increased risk of RCC in allelic, dominant, homozygote, and recessive models (B vs. A: $O R=1.198,95 \% \mathrm{CI}=1.074-1.336, P_{A}=$ $1.199 \mathrm{E}-03$; $\mathrm{BA}+\mathrm{BB}$ vs. $\mathrm{AA}: \mathrm{OR}=1.205,95 \% \mathrm{CI}=1.046-1.389$, $P_{A}=9.705 \mathrm{E}-03$; $\mathrm{BB}$ vs. $\mathrm{AA}: \mathrm{OR}=1.383,95 \% \mathrm{CI}=1.111-1.721$, $P_{A}=3.699 \mathrm{E}-03 ; \mathrm{BB}$ vs. $\mathrm{BA}+\mathrm{AA}: O R=1.278,95 \% \mathrm{CI}=$ $\left.1.041-1.570, P_{A}=1.930 \mathrm{E}-02\right)$.

\section{VEGF-rs699947}

Overall, there was no significant association between VEGFrs699947 polymorphism and the risk of urogenital neoplasms. Nonetheless, an increased risk of urogenital carcinomas for Asian populations in allelic, heterozygote, dominant, and homozygote models were found in the stratification analysis by ethnicity (B vs. $\mathrm{A}: \mathrm{OR}=1.277,95 \% \mathrm{CI}=1.158-1.408, P_{A}=9.201 \mathrm{E}-07$; $\mathrm{BA}$ vs. $\mathrm{AA}: \mathrm{OR}=1.352,95 \% \mathrm{CI}=1.166-1.568, P_{A}=6.730 \mathrm{E}-05 ; \mathrm{BB}+$ $\mathrm{BA}$ vs. $\mathrm{AA}: \mathrm{OR}=1.410,95 \% \mathrm{CI}=1.226-1.620, P_{A}=1.339 \mathrm{E}-06$ and $\mathrm{BB}$ vs. $\mathrm{AA}: \mathrm{OR}=1.572,95 \% \mathrm{CI}=1.279-1.931, P_{A}=1.706 \mathrm{E}-$ $05)$. Moreover, when the stratification analysis conducted by cancer type, we also identified an increased risk of RCC in allelic, heterozygote, dominant, homozygote, and recessive models (B vs. A: $O R=1.312,95 \% \mathrm{CI}=1.186-1.450, P_{A}=1.311 \mathrm{E}-07$; $\mathrm{BA}$ vs. $\mathrm{AA}: \mathrm{OR}=1.306,95 \% \mathrm{CI}=1.122-1.521, P_{A}=5.669 \mathrm{E}-04 ; \mathrm{BB}+$ $\mathrm{BA}$ vs. $\mathrm{AA}: \mathrm{OR}=1.394,95 \% \mathrm{CI}=1.209-1.607, P_{A}=4.602 \mathrm{E}-06$; $\mathrm{BB}$ vs. $\mathrm{AA}: \mathrm{OR}=1.687,95 \% \mathrm{CI}=1.372-2.075, P_{A}=7.220 \mathrm{E}-07$ and $\mathrm{BB}$ vs. $\mathrm{BA}+\mathrm{AA}: \mathrm{OR}=1.435,95 \% \mathrm{CI}=1.188-1.733, P_{A}=$ 1.791E-04).

\section{VEGF-rs10434, VEGF-rs1570360, VEGF-rs833061, and HIF1a-rs11549465}

There was no significant association between VEGF-rs10434, VEGF-rs1570360, VEGF-rs2010963, VEGF-rs833061, and HIF $1 \alpha$-rs 11549465 polymorphisms and the risk of urogenital carcinomas. Furthermore, in the subgroup analysis by ethnicity, source of controls, cancer type or HWE status, similar results were also obtained.

\section{Sensitivity Analysis and Publication Bias}

In order to assess the stability of current meta-analysis result, sensitivity analysis was performed. The influence of the individual dataset on the pooled ORs was investigated after sequentially excluding each single case-control study. The study material alteration did not change the corresponding pooled ORs for all 12 polymorphisms (Supplementary Figure 1 and Supplementary Table 4). Furthermore, Begg's funnel plot and Egger's regression test were performed to evaluate the publication bias (Begg and Mazumdar, 1994; Egger et al., 1997). As for these 12 polymorphisms, no evidence of publication bias was identified by viewing the shape of Begg's funnel plot, which was further validated by Egger's regression test (Supplementary Figure 2 and Supplementary Table 5).

\section{LD Analyses Across Populations}

To better understand the quantitative synthesis, we performed $\mathrm{LD}$ analysis to test for the existence of bins in the region comprising these polymorphisms of each angiogenesis related genes (VEGF-rs10434, VEGF-rs1570360, VEGF-rs2010963, VEGF-rs3025039, VEGF-rs699947, VEGF-rs833061, HIF1 $\alpha$ rs11549465, HIF1 $\alpha$-rs11549467, eNOS-rs1799983, and eNOSrs2070744), respectively. LD plots for polymorphisms in each gene were presented in Figure 2 and Supplementary Table 6. Although we have uncovered significant LD for several polymorphisms in separate genes, such as VEGF, they were not statistically associated with urological neoplasms' risk in current work. As for the two significant polymorphisms (eNOS-Intron 4a/b VNTR and eNOS-rs2070744), LD analysis cannot be performed because eNOS-Intron 4a/b VNTR polymorphism was mismatched.

\section{DISCUSSION}

Angiogenesis is well-recognized as a key element for sustained tumor growth and a critical factor for tumor metastasis (McConkey et al., 2016; De Palma et al., 2017). Our previous studies also demonstrated upregulation of angiogenesis genes, e.g., VEGF played vital roles in bladder cancer progression ( $\mathrm{Zu}$ et al., 2006; Lei et al., 2015; Zhou et al., 2015; Chen et al., 2016; Long et al., 2016). Other researchers also suggested that polymorphisms in angiogenesis pathway genes might be an important risk factors for the initiation and progression of urogenital neoplasms (Jacobs et al., 2008; Jaiswal et al., 2013; Orlandi et al., 2013; Dornbusch et al., 2016; Gong et al., 2017).

Some investigators have conducted case-control studies to evaluate the association between polymorphisms in angiogenesis related genes and the risk of urological tumors (Foley et al., 
2009; Henríquez-Hernández et al., 2012; Li et al., 2012). However, most of prior studies addressed on limited polymorphisms in single angiogenesis related gene while neglected potential multiple gene's influence on urological carcinogenesis. Xian et al. found VEGF-rs3025039 genetic variant was associated with increased risk of RCC (Xian et al., 2015), but another study revealed no association (Abe et al., 2002). Li P et al. reported HIF1 $\alpha$-rs11549467 rather than HIF1 $\alpha$-rs11549465 polymorphism increased prostate cancer susceptibility (Li et al., 2012). Other studies failed to detect any association between these two polymorphisms and the risk of urinary cancers (Clifford et al., 2001; Morris et al., 2009). One study showed the eNOS-rs1799983 was associated with increased prostate cancer risk (Medeiros et al., 2002), while another study data suggested no association (Brankovic et al., 2013). HRASrs12628 polymorphism could mediate urinary bladder cancer development and predict tumors advancing (Amasyali et al., 2012), but another study showed no significant correlation (Sanyal et al., 2004). In the current study, we presented a comprehensive meta-analysis for 12 polymorphisms in four VEGF/hypoxia/angiogenesis pathway genes (VEGF, HIF1 $\alpha$, eNOS, and HRAS) including 96 case-control studies to examine the precise associations between these polymorphisms and risk of urogenital neoplasms.

Previous studies revealed that eNOS could modulate cancerrelated events, such as VEGF-induced angiogenesis, invasion, and metastasis (Jadeski et al., 2000; Duda et al., 2004). The eNOS-rs2070744 polymorphism is a point mutation of thymine to cytosine $(\mathrm{T}>\mathrm{C})$ at -786 nucleotide in the $5^{\prime}$-flanking region of the eNOS gene (Nakayama et al., 1999). This mutation position in eNOS promoter region can alter gene activity and serum NO level, indicating the CC homozygote carriers may have an increased risk of cancer (Zhang et al., 2014). Present meta-analysis indicated that eNOS-rs2070744 polymorphism conferred a significantly increased overall risk to urogenital neoplasms. This is consistent with several previously published studies (Ryk et al., 2011; Brankovic et al., 2013; Safarinejad et al., 2013; Polat et al., 2015; Diler and Oden, 2016). The eNOS-Intron $4 \mathrm{a} / \mathrm{b}$ VNTR polymorphism is a variable number of tandem repeats $(27 \mathrm{nt})$ in intron 4 participating in basal plasma NO generation (Wang et al., 1997). Our final analysis results suggested that this polymorphism was related to an increased risk of urogenital neoplasms in recessive model. However, 6 case-control studies for eNOS-Intron 4a/b VNTR polymorphism enrolled in our study, there were two studies showed no significant relationship between this polymorphism and urogenital neoplasms (Sanli et al., 2011; Diler and Oden, 2016).

Although no significant association was uncovered between the association between VEGF-rs699947 polymorphism and the risk of urogenital neoplasms. In the subgroup analysis by ethnicity, we found an increased risk of urogenital neoplasms in Asian populations. Moreover, when the stratification analysis conducted by cancer type, we also identified an increased risk for RCC subtype. Similar results were found between VEGFrs3025039 polymorphism and risk of urogenital neoplasms. Nevertheless, in the subgroup analysis of ethnicity, we observed an increased risk of urogenital neoplasms in allelic model for Asian populations. Moreover, in stratification analysis by source of control, an increased risk of urogenital neoplasms for $\mathrm{H}$ B groups was also uncovered. Deviations in HWE status were influenced by methodological problems, such as the genotyping errors, the population stratification or selection bias, et al. Thus, we have conducted subgroup analyses by HWE status. For the HRAS-rs12628 polymorphism, we identified an increased risk of urogenital neoplasms in the dominant model for HWE (Y) groups.

While for VEGF (rs3025039, rs10434, rs1570360, rs2010963, and rs833061), HIF1 $\alpha$ (rs11549465 and rs11549467), HRASrs12628 and eNOS-rs1799983 polymorphisms, our meta-analysis indicated there were no significant associations between them and urogenital neoplasms susceptibility even in subgroup analysis by ethnicity, HWE status, source of controls and cancer type (multiple testing $P$-value according to Bonferroni correction $[P<0.05 /(12$ polymorphisms $\times 5$ models $)]$ was considered as statistically significant). However, we also prefer to identify markers for specific tumors (eg. RCC, $\mathrm{BCa}$, and $\mathrm{PCa})$. For these SNPs, $P_{A}<0.05$ was considered as statistically significant for cancer type subgroup analysis. Results suggested VEGF-rs699947, VEGF-rs3025039, and VEGFrs2010963 polymorphisms may be a potential risk factor for RCC. And eNOS-rs2070744, eNOS-Intron 4a/b VNTR, eNOSrs1799983, and HRAS-rs12628 polymorphisms may be a risk factor for BCa. In addition, eNOS-rs2070744 and HIF1ars11549467 polymorphisms may be a risk factor for PCa. Accordingly, these subgroups results suggested these SNPs might be used as potential diagnostic markers for RCC, BCa, and $\mathrm{PCa}$, respectively. There are several important advantages for the current meta-analysis. First and foremost, we implemented a comprehensive database search to identify all eligible studies in the VEGF/hypoxia/angiogenesis pathway, making our metaanalysis more substantial and persuasive. Second, all included studies were assessed by Newcastle Ottawa Scale, aiming to exclude low quality studies and elevate the overall quality. Third, various subgroup analyses based on ethnicity, HWE status, source of controls and cancer type were performed, trying to further stratify the sources of heterogeneity. Fourth, in order to making our analysis more accurate, the recognized formula was performed to adjust the results. In addition, sensitivity analysis was applied to confirm the stability of included studies, and Begg's funnel plot and Egger's test was utilized to analyze publication bias.

However, several limitations should also be noted in our present meta-analysis. First, for several polymorphisms, particularly when the case number in the studies was small, it may result in an insufficient power for identifying weak association between these polymorphisms and urogenital neoplasms susceptibility. Second, we currently didn't validate these polymorphisms with related clinical consequences. In the follow-up study, we will focus on the functional aspects of how these polymorphisms affect genes expression and ultimately associate with tumorigenesis. Third, all of the included studies were restricted in English, exclusion of other languages studies may increase the publication bias. Fourth, we didn't consider 
several potential confounding factors in this study, such as the age, gender, smoking habit, drinking status, and environmental factors, etc. This limited us further study the genetic and environmental interaction model. Therefore, the current result should be cautious interpreted.

In summary, in conjunction with other studies, current meta-analysis results suggest that eNOS-rs2070744 and eNOSIntron $4 \mathrm{a} / \mathrm{b}$ VNTR polymorphisms are associated with elevated risk of urogenital carcinomas. In addition, VEGF-rs699947 polymorphism was also identified as an risk factor for renal carcinoma. Further well-designed case-control studies with large population size are warranted to strengthen our findings.

\section{AUTHOR CONTRIBUTIONS}

$\mathrm{J}-\mathrm{BC}, \mathrm{MZ}$, and $\mathrm{X}-\mathrm{BZ}$ conceived and designed the study, performed the literature search and data extraction. J-BC, MZ, YC, P-HL, Y-WQ, CL, XC, W-BR, and Q-QL performed the meta-analysis and drafted the manuscript. L-FL, M-FC, H-QC, and $\mathrm{X}-\mathrm{BZ}$ revised the manuscript. $\mathrm{H}-\mathrm{QC}$ and $\mathrm{X}-\mathrm{BZ}$ final approval of the version to be submitted.

\section{ACKNOWLEDGMENTS}

This work was supported by the National Key R\&D Program of China (2016YFC0902603), the National Natural Science Foundation of China (81572523), the Hunan Province Funds for Distinguished Young Scientists of China (2016JJ1026), the Fundamental Research Funds for the Central Universities of

\section{REFERENCES}

Abe, A., Sato, K., Habuchi, T., Wang, L., Li, Z., Tsuchiya, N., et al. (2002). Single nucleotide polymorphisms in the $3^{\prime}$ untranslated region of vascular endothelial growth factor gene in Japanese population with or without renal cell carcinoma. Tohoku J. Exp. Med. 198, 181-190. doi: 10.1620/tjem.198.181

Ajaz, S., Khaliq, S., Abid, A., Hassan, A. S., Hashmi, A., Sultan, G., et al. (2011). Association of a single-nucleotide polymorphism in the promoter region of the VEGF gene with the risk of renal cell carcinoma. Genet. Test. Mol. Biomarkers 15, 653-657. doi: 10.1089/gtmb.2011.0029

Amasyali, A. S., Kucukgergin, C., Erdem, S., Sanli, O., Seckin, S., and Nane, I. (2012). Nitric oxide synthase (eNOS4a/b) gene polymorphism is associated with tumor recurrence and progression in superficial bladder cancer cases. J. Urol. 188, 2398-2403. doi: 10.1016/j.juro.2012.07.096

Begg, C. B., and Mazumdar, M. (1994). Operating characteristics of a rank correlation test for publication bias. Biometrics 50, 1088-1101. doi: $10.2307 / 2533446$

Branković, A., Brajušković, G., Nikolić, Z., Vukotić, V., Cerović, S., Savić-Pavićević D., et al. (2013). Endothelial nitric oxide synthase gene polymorphisms and prostate cancer risk in Serbian population. Int. J. Exp. Pathol. 94, 355-361. doi: 10.1111/iep.12045

Bruyère, F., Hovens, C. M., Marson, M. N., d'Arcier, B. F., Costello, A. J., Watier, H., et al. (2010). VEGF polymorphisms are associated with an increasing risk of developing renal cell carcinoma. J. Urol. 184, 1273-1278. doi: 10.1016/j.juro.2010.06.009

Ceylan, G. G., Ceylan, C., Gülmemmedov, B., Tonyali, S., Odabaş, O., Gozalan, A., et al. (2016). Polymorphisms of eNOS, catalase, and myeloperoxidase genes in prostate cancer in Turkish men: preliminary results. Genet. Mol. Res. 15:3. doi: 10.4238/gmr.150 38543
Central South University (2016zzts121), and the Natural Science Foundation of Guangdong Province, China (2017A030313800).

\section{SUPPLEMENTARY MATERIAL}

The Supplementary Material for this article can be found online at: https://www.frontiersin.org/articles/10.3389/fphys. 2018.00715/full\#supplementary-material

Supplementary Figure 1 | Sensitivity analysis for VEGF-rs10434 (A), VEGF-rs1570360 b, VEGF-rs2010963 (C), VEGF-rs3025039 (D), VEGF-rs699947 (E), VEGF-rs833061 (F), HIF1 $\alpha$-rs11549465 (G), HIF1 $\alpha$-rs11549467 (H), eNOS-rs1799983 (I), eNOS-rs2070744 (J), eNOS-Intron 4a/b VNTR (K), HRAS-rs12628 (L) polymorphism and the risk of urogenital carcinomas (allelic comparison B vs. A).

Supplementary Figure 2 | Begg's funnel plot for publication bias for VEGF-rs10434 (A), VEGF-rs1570360 (B), VEGF-rs2010963 (C), VEGF-rs3025039 (D), VEGF-rs699947 (E), VEGF-rs833061 (F), HIF1 $\alpha$-rs11549465 (G), HIF1 $\alpha$-rs11549467 (H), eNOS-rs1799983 (I), eNOS-rs2070744 (J), eNOS-Intron 4a/b VNTR (K), HRAS-rs12628 (L) polymorphism (allelic comparison B vs. A).

Supplementary Table 1 | Search strategies for each gene and the finally eligible articles included.

Supplementary Table 2 | Methodological quality of the included studies according to the Newcastle-Ottawa Scale.

Supplementary Table $\mathbf{3}$ | Results of meta-analysis for polymorphisms in VEGF/ Hypoxia/Angiogenesis genes and risk of Urogenital Carcinomas.

Supplementary Table 4 | Details of the sensitivity analyses for the polymorphisms in VEGF/hypoxia/angiogenesis genes and the risk of urogenital carcinomas.

Supplementary Table 5 $\mid P$-values of the Egger' test.

Supplementary Table 6 | Summary of LD analyses.

Chau, C. H., Permenter, M. G., Steinberg, S. M., Retter, A. S., Dahut, W. L., Price, D. K., et al. (2005). Polymorphism in the hypoxia-inducible factor $1 \alpha$ gene may confer susceptibility to androgen-independent prostate cancer. Cancer Biol. Ther. 4, 1222-1225. doi: 10.4161/cbt.4.11.2091

Chen, J., Wang, L., Tang, Y., Gong, G., Liu, L., Chen, M., et al. (2016). Maspin enhances cisplatin chemosensitivity in bladder cancer T24 and 5637 cells and correlates with prognosis of muscle-invasive bladder cancer patients receiving cisplatin based neoadjuvant chemotherapy. J. Exp. Clin. Cancer Res. 35:2. doi: 10.1186/s13046-015-0282-y

Clifford, S. C., Astuti, D., Hooper, L., Maxwell, P. H., Ratcliffe, P. J., and Maher, E. R. (2001). The pVHL-associated SCF ubiquitin ligase complex: molecular genetic analysis of elongin B and C, Rbx1 and HIF-1alpha in renal cell carcinoma. Oncogene 20, 5067-5074. doi: 10.1038/sj.onc. 1204602

De Palma, M., Biziato, D., and Petrova, T. V. (2017). Microenvironmental regulation of tumour angiogenesis. Nat. Rev. Cancer 17, 457-474. doi: $10.1038 /$ nrc. 2017.51

Diler, S. B., and Öden, A. (2016). The T-786C, G894T, and intron 4 VNTR (4a/b) polymorphisms of the endothelial nitric oxide synthase gene in prostate cancer cases. Genetika 52, 249-254. doi: 10.1134/S1022795416020022

Dornbusch, J., Walter, M., Gottschalk, A., Obaje, A., Junker, K., Ohlmann, C. H., et al. (2016). Evaluation of polymorphisms in angiogenesis-related genes as predictive and prognostic markers for sunitinib-treated metastatic renal cell carcinoma patients. J. Cancer Res. Clin. Oncol. 142, 1171-1182. doi: 10.1007/s00432-016-2137-0

Duda, D. G., Fukumura, D., and Jain, R. K. (2004). Role of eNOS in neovascularization: NO for endothelial progenitor cells. Trends Mol. Med. 10, 143-145. doi: 10.1016/j.molmed.2004.02.001

Dy, G. W., Gore, J. L., Forouzanfar, M. H., Naghavi, M., and Fitzmaurice, C. (2017). Global burden of urologic cancers, 1990-2013. Eur. Urol. 71, 437-446. doi: 10.1016/j.eururo.2016.10.008 
Egger, M., Davey Smith, G., Schneider, M., and Minder, C. (1997). Bias in metaanalysis detected by a simple, graphical test. BMJ 315, 629-634.

Foley, R., Marignol, L., Thomas, A. Z., Cullen, I. M., Perry, A. S., Tewari, P., et al. (2009). The HIF-1alpha C1772T polymorphism may be associated with susceptibility to clinically localised prostate cancer but not with elevated expression of hypoxic biomarkers. Cancer Biol. Ther. 8, 118-124. doi: 10.4161/cbt.8.2.7086

Fraga, A., Ribeiro, R., Príncipe, P., Lobato, C., Pina, F., Maurício, J., et al. (2014). The HIF1A functional genetic polymorphism at locus +1772 associates with progression to metastatic prostate cancer and refractoriness to hormonal castration. Eur. J. Cancer 50, 359-365. doi: 10.1016/j.ejca.2013.09.001

Fukuda, H., Tsuchiya, N., Narita, S., Kumazawa, T., Horikawa, Y., Inoue, T., et al. (2007). Clinical implication of vascular endothelial growth factor T-460C polymorphism in the risk and progression of prostate cancer. Oncol. Rep. 18, 1155-1163. doi: 10.3892/or.18.5.1155

García-Closas, M., Malats, N., Real, F. X., Yeager, M., Welch, R., Silverman, D., et al. (2007). Large-scale evaluation of candidate genes identifies associations between VEGF polymorphisms and bladder cancer risk. PLoS Genet. 3:e29. doi: 10.1371/journal.pgen.0030029

Gong, M., Dong, W., Shi, Z., Qiu, S., and Yuan, R. (2017). Vascular endothelial growth factor gene polymorphisms and the risk of renal cell carcinoma: evidence from eight case-control studies. Oncotarget 8, 8447-8458. doi: 10.18632 /oncotarget. 14263

Haque, S., Mandal, R. K., Akhter, N., Panda, A. K., Hussain, A., Khan, S., et al. (2015). G894T and 4a/b polymorphisms of NOS3 gene are not associated with cancer risk: a meta-analysis. Asian Pac. J. Cancer Prev. 16, 2929-2937. doi: 10.7314/APJCP.2015.16.7.2929

Henríquez-Hernández, L. A., Navarro, P., Luzardo, O. P., Alvarez-León, E. E., Boada, L. D., Zumbado, M., et al. (2012). Polymorphisms of glutathione S-transferase mu and theta, MDR1 and VEGF genes as risk factors of bladder cancer: a case-control study. Urol. Oncol. 30, 660-665. doi: 10.1016/j.urolonc.2010.08.028

Higgins, J. P., Thompson, S. G., Deeks, J. J., and Altman, D. G. (2003). Measuring inconsistency in meta-analyses. BMJ 327, 557-560. doi: $10.1136 / \mathrm{bmj} .327 .7414 .557$

Ianni, M., Porcellini, E., Carbone, I., Potenzoni, M., Pieri, A. M., Pastizzaro, C. D., et al. (2013). Genetic factors regulating inflammation and DNA methylation associated with prostate cancer. Prostate Cancer Prostatic Dis. 16, 56-61. doi: $10.1038 /$ pcan.2012.30

Jacobs, E. J., Hsing, A. W., Bain, E. B., Stevens, V. L., Wang, Y., Chen, J., et al. (2008). Polymorphisms in angiogenesis-related genes and prostate cancer. Cancer Epidemiol. Biomarkers Prev. 17, 972-977. doi: 10.1158/1055-9965.EPI-07-2787

Jadeski, L. C., Hum, K. O., Chakraborty, C., and Lala, P. K. (2000). Nitric oxide promotes murine mammary tumour growth and metastasis by stimulating tumour cell migration, invasiveness and angiogenesis. Int. J. Cancer 86, 30-39. doi: 10.1002/(SICI) 1097-0215(20000401)86:1\&lt;30::AID-IJC5\&gt;3.0.CO;2-I

Jaiswal, P. K., Tripathi, N., Shukla, A., and Mittal, R. D. (2013). Association of single nucleotide polymorphisms in vascular endothelial growth factor gene with bladder cancer risk. Med. Oncol. 30:509. doi: 10.1007/s12032-013-0509-8

Johne, A., Roots, I., and Brockmöller, J. (2003). A single nucleotide polymorphism in the human $\mathrm{H}$-ras proto-oncogene determines the risk of urinary bladder cancer. Cancer Epidemiol. Biomarkers Prev. 12, 68-70.

Kim, E. J., Jeong, P., Quan, C., Kim, J., Bae, S. C., Yoon, S. J., et al. (2005). Genotypes of TNF-alpha, VEGF, hOGG1, GSTM1, and GSTT1: useful determinants for clinical outcome of bladder cancer. Urology 65, 70-75. doi: 10.1016/j.urology.2004.08.005

Lee, K. M., Kang, D., Park, S. K., Berndt, S. I., Reding, D., Chatterjee, N., et al. (2009). Nitric oxide synthase gene polymorphisms and prostate cancer risk. Carcinogenesis 30, 621-625. doi: 10.1093/carcin/bgp028

Lei, Y., Li, B., Tong, S., Qi, L., Hu, X., Cui, Y., et al. (2015). miR-101 suppresses vascular endothelial growth factor $C$ that inhibits migration and invasion and enhances cisplatin chemosensitivity of bladder cancer cells. PLOS ONE 10:e0117809. doi: 10.1371/journal.pone.0117809

Li, D., Liu, J., Zhang, W., Ren, J., Yan, L., Liu, H., et al. (2013). Association between HIF1A P582S and A588T polymorphisms and the risk of urinary cancers: a meta-analysis. PLoS ONE 8:e63445. doi: 10.1371/journal.pone.0063445
Li, H., Bubley, G. J., Balk, S. P., Gaziano, J. M., Pollak, M., Stampfer, M. J., et al. (2007). Hypoxia-inducible factor-1alpha (HIF-1alpha) gene polymorphisms, circulating insulin-like growth factor binding protein (IGFBP)-3 levels and prostate cancer. Prostate 67, 1354-1361. doi: 10.1002/pros.20589

Li, P., Cao, Q., Shao, P. F., Cai, H. Z., Zhou, H., Chen, J. W., et al. (2012). Genetic polymorphisms in HIF1A are associated with prostate cancer risk in a Chinese population. Asian J. Androl. 14, 864-869. doi: 10.1038/aja.2012.101

Lin, C. C., Wu, H. C., Tsai, F. J., Chen, H. Y., and Chen, W. C. (2003). Vascular endothelial growth factor gene- $460 \mathrm{C} / \mathrm{T}$ polymorphism is a biomarker for prostate cancer. Urology 62, 374-377. doi: 10.1016/S0090-4295(03)00268-1

Long, X., Zu, X., Li, Y., He, W., Hu, X., Tong, S., et al. (2016). Epidermal growth factor receptor and Ki-67 as predictive biomarkers identify patients who will be more sensitive to intravesical instillations for the prevention of bladder cancer recurrence after radical nephroureterectomy. PLOS ONE 11:e0166884. doi: 10.1371/journal.pone.0166884

Lu, G., Dong, Y., Zhang, Q., Jiao, L., Yang, S., and Shen, B. (2015). Predictive value of vascular endothelial growth factor polymorphisms on the risk of renal cell carcinomas: a case-control study. Tumour Biol. 36, 8645-8652. doi: 10.1007/s13277-015-3431-1

Marangoni, K., Neves, A. F., Cardoso, A. M., Santos, W. K., Faria, P. C., and Goulart, L. R. (2006). The endothelial nitric oxide synthase Glu-298-Asp polymorphism and its mRNA expression in the peripheral blood of patients with prostate cancer and benign prostatic hyperplasia. Cancer Detect. Prev. 30, 7-13. doi: 10.1016/j.cdp.2005.09.004

Martinez-Fierro, M. L., Garza-Veloz, I., Rojas-Martinez, A., Ortiz-Lopez, R., Castruita-de la Rosa, C., Ortiz-Castro, Y., et al. (2013). Positive association between vascular endothelial growth factor (VEGF)-2578 C/A variant and prostate cancer. Cancer Biomark. 13, 235-241. doi: 10.3233/CBM-130348

McCarron, S. L., Edwards, S., Evans, P. R., Gibbs, R., Dearnaley, D. P., Dowe, A., et al. (2002). Influence of cytokine gene polymorphisms on the development of prostate cancer. Cancer Res. 62, 3369-3372.

McConkey, D. J., Choi, W., Ochoa, A., and Dinney, C. P. N. (2016). Intrinsic subtypes and bladder cancer metastasis. Asian J. Urol. 3, 260-267. doi: 10.1016/j.ajur.2016.09.009

Medeiros, R., Morais, A., Vasconcelos, A., Costa, S., Pinto, D., Oliveira, J., et al. (2002). Endothelial nitric oxide synthase gene polymorphisms and genetic susceptibility to prostate cancer. Eur. J. Cancer Prev. 11, 343-350. doi: 10.1097/00008469-200208000-00005

Morris, M. R., Hughes, D. J., Tian, Y. M., Ricketts, C. J., Lau, K. W., Gentle, D., et al. (2009). Mutation analysis of hypoxia-inducible factors HIF1A and HIF2A in renal cell carcinoma. Anticancer Res. 29, 4337-4343.

Nadaoka, J., Horikawa, Y., Saito, M., Kumazawa, T., Inoue, T., Narita, S., et al. (2008). Prognostic significance of HIF-1 alpha polymorphisms in transitional cell carcinoma of the bladder. Int. J. Cancer 122, 1297-1302. doi: $10.1002 /$ ijc. 23256

Nakayama, M., Yasue, H., Yoshimura, M., Shimasaki, Y., Kugiyama, K., Ogawa, H., et al. (1999). T-786->C mutation in the $5^{\prime}$-flanking region of the endothelial nitric oxide synthase gene is associated with coronary spasm. Circulation 99, 2864-2870.

Nicholson, B., and Theodorescu, D. (2004). Angiogenesis and prostate cancer tumor growth. J. Cell. Biochem. 91, 125-150. doi: 10.1002/jcb.10772

Onen, I. H., Konac, E., Eroglu, M., Guneri, C., Biri, H., and Ekmekci, A. (2008). No association between polymorphism in the vascular endothelial growth factor gene at position -460 and sporadic prostate cancer in the Turkish population. Mol. Biol. Rep. 35, 17-22. doi: 10.1007/s11033-006-9046-2

Orlandi, P., Fontana, A., Fioravanti, A., Di Desidero, T., Galli, L., Derosa, L., et al. (2013). VEGF-A polymorphisms predict progression-free survival among advanced castration-resistant prostate cancer patients treated with metronomic cyclophosphamide. Br. J. Cancer 109, 957-964. doi: 10.1038/bjc.2013.398

Orr-Urtreger, A., Bar-Shira, A., Matzkin, H., and Mabjeesh, N. J. (2007). The homozygous P582S mutation in the oxygen-dependent degradation domain of HIF-1 alpha is associated with increased risk for prostate cancer. Prostate 67, 8-13. doi: 10.1002/pros.20433

Pandith, A. A., Shah, Z. A., Khan, N. P., Baba, K. M., Wani, M. S., and Siddiqi, M. A. (2013). HRAS T81C polymorphism modulates risk of urinary bladder cancer and predicts advanced tumors in ethnic Kashmiri population. Urol. Oncol. 31, 487-492. doi: 10.1016/j.urolonc.2011.03.004 
Polat, F., Diler, S. B., Azazi, I., and Öden, A. (2015). T-786C, G894T, and intron 4 VNTR $(4 \mathrm{a} / \mathrm{b})$ polymorphisms of the endothelial nitric oxide synthase gene in bladder cancer cases. Asian Pac. J. Cancer Prev. 16, 2199-2202. doi: 10.7314/APJCP.2015.16.6.2199

Qin, C., Cao, Q., Ju, X., Wang, M., Meng, X., Zhu, J., et al. (2012). The polymorphisms in the VHL and HIF1A genes are associated with the prognosis but not the development of renal cell carcinoma. Ann. Oncol. 23, 981-989. doi: 10.1093/annonc/mdr325

Qin, C., Chen, J., Li, J., Ju, X., Zhang, S., Cao, Q., et al. (2014). Variants in angiogenesis-related genes and the risk of clear cell renal cell carcinoma. Mutagenesis 29, 419-425. doi: 10.1093/mutage/geu046

Ricketts, C., Zeegers, M. P., Lubinski, J., and Maher, E. R. (2009). Analysis of germline variants in CDH1, IGFBP3, MMP1, MMP3, STK15 and VEGF in familial and sporadic renal cell carcinoma. PLoS ONE 4:e6037. doi: 10.1371/journal.pone.0006037

Ruggiero, D., Dalmasso, C., Nutile, T., Sorice, R., Dionisi, L., Aversano, M., et al. (2011). Genetics of VEGF serum variation in human isolated populations of cilento: importance of VEGF polymorphisms. PLoS ONE 6:e16982. doi: 10.1371/journal.pone.0016982

Ryk, C., Wiklund, N. P., Nyberg, T., and de Verdier, P. J. (2011). Polymorphisms in nitric-oxide synthase 3 may influence the risk of urinary-bladder cancer. Nitric Oxide 25, 338-343. doi: 10.1016/j.niox.2011.06.003

Sáenz-López, P., Vazquez, F., Cozar, J. M., Carretero, R., Garrido, F., and RuizCabello, F. (2013). VEGF polymorphisms are not associated with an increased risk of developing renal cell carcinoma in Spanish population. Hum. Immunol. 74, 98-103. doi: 10.1016/j.humimm.2012.10.014

Safarinejad, M. R., Safarinejad, S., Shafiei, N., and Safarinejad, S. (2013). Effects of the T-786C, G894T, and Intron 4 VNTR $(4 \mathrm{a} / \mathrm{b})$ polymorphisms of the endothelial nitric oxide synthase gene on the risk of prostate cancer. Urol. Oncol. 31, 1132-1140. doi: 10.1016/j.urolonc.2012.01.002

Sanli, O., Kucukgergin, C., Gokpinar, M., Tefik, T., Nane, I., and Seckin, S. (2011). Despite the lack of association between different genotypes and the presence of prostate cancer, endothelial nitric oxide synthase $a / b$ (eNOS4a/b) polymorphism may be associated with advanced clinical stage and bone metastasis. Urol. Oncol. 29, 183-188. doi: 10.1016/j.urolonc.2009.04.011

Sanyal, S., Festa, F., Sakano, S., Zhang, Z., Steineck, G., Norming, U., et al. (2004). Polymorphisms in DNA repair and metabolic genes in bladder cancer. Carcinogenesis 25, 729-734. doi: 10.1093/carcin/bgh058

Sfar, S., Hassen, E., Saad, H., Mosbah, F., and Chouchane, L. (2006). Association of VEGF genetic polymorphisms with prostate carcinoma risk and clinical outcome. Cytokine 35, 21-28. doi: 10.1016/j.cyto.2006.07.003

Shamseer, L., Moher, D., Clarke, M., Ghersi, D., Liberati, A., Petticrew, M., et al. (2015). Preferred reporting items for systematic review and meta-analysis protocols (PRISMA-P) 2015: elaboration and explanation. BMJ 349:g7647. doi: 10.1136/bmj.g7647

Shen, B. L., Qu, Q. S., Miao, S. Z., and Zhang, Y. X. (2015). Association between SNPs in vascular endothelial growth factor polymorphisms and risk of renal cell carcinoma: a case-control study. Genet. Mol. Res. 14, 11119-11125. doi: 10.4238/2015.September.22.5

Siegel, R. L., Miller, K. D., and Jemal, A. (2017). Cancer statistics, 2017. CA Cancer J. Clin. 67, 7-30. doi: 10.3322/caac.21387

Stadler, Z. K., Thom, P., Robson, M. E., Weitzel, J. N., Kauff, N. D., Hurley, K. E., et al. (2010). Genome-wide association studies of cancer. J. Clin. Oncol. 28, 4255-4267. doi: 10.1200/JCO.2009.25.7816

Sun, J., Zheng, S. L., Wiklund, F., Isaacs, S. D., Purcell, L. D., Gao, Z., et al. (2008). Evidence for two independent prostate cancer risk-associated loci in the HNF1B gene at 17q12. Nat. Genet. 40, 1153-1155. doi: 10.1038/ ng. 214

Traczyk, M., Borkowska, E., Rozniecki, M., Purpurowicz, R., Jedrzejczyk, A., Marks, P., et al. (2012). Polymorphic variants of H-RAS protooncogene and their possible role in bladder cancer etiology. Cent. Eur. J. Urol. 65, 84-87. doi: 10.5173/ceju.2012.02.art6

VanCleave, T. T., Moore, J. H., Benford, M. L., Brock, G. N., Kalbfleisch, T., Baumgartner, R. N., et al. (2010). Interaction among variant vascular endothelial growth factor (VEGF) and its receptor in relation to prostate cancer risk. Prostate 70, 341-352. doi: 10.1002/pros.21067

Verim, L., Toptas, B., Ozkan, N. E., Cacina, C., Turan, S., Korkmaz, G., et al. (2013). Possible relation between the NOS3 gene GLU298ASP polymorphism and bladder cancer in Turkey. Asian Pac. J. Cancer Prev. 14, 665-668. doi: 10.7314/APJCP.2013.14.2.665

Wang, X. L., Mahaney, M. C., Sim, A. S., Wang, J., Wang, J., Blangero, J. et al. (1997). Genetic contribution of the endothelial constitutive nitric oxide synthase gene to plasma nitric oxide levels. Arterioscler. Thromb. Vasc. Biol. 17, 3147-3153. doi: 10.1161/01.ATV.17.11.3147

Wang, Y. H., Yeh, S. D., Wu, M. M., Liu, C. T., Shen, C. H., Shen, K. H., et al. (2013). Comparing the joint effect of arsenic exposure, cigarette smoking and risk genotypes of vascular endothelial growth factor on upper urinary tract urothelial carcinoma and bladder cancer. J. Hazard. Mater. 262, 1139-1146. doi: 10.1016/j.jhazmat.2012.08.056

Xian, W., Zheng, H., and Wu, W. J. (2015). Predictive value of vascular endothelial growth factor polymorphisms on the risk of renal cell carcinomas. Genet. Mol. Res. 14, 7634-7642. doi: 10.4238/2015.July.13.8

Yang, Y., Zhang, X., Song, D., and Wei, J. (2014). Association between vascular endothelial growth factor gene polymorphisms and bladder cancer risk. Mol. Clin. Oncol. 2, 501-505. doi: 10.3892/mco.2014.296

Zhang, L., Chen, L. M., Wang, M. N., Chen, X. J., Li, N., Huang, Y. D., et al. (2014). The G894t, T-786c and 4b/a polymorphisms in Enos gene and cancer risk: a meta-analysis. J. Evid. Based Med. 7, 263-269. doi: 10.1111/jebm.12126

Zhang, Y., Jin, M., Liu, B., Ma, X., Yao, K., Li, Q., et al. (2008). Association between H-RAS T81C genetic polymorphism and gastrointestinal cancer risk: a population based case-control study in China. BMC Cancer 8:256. doi: 10.1186/1471-2407-8-256

Zhao, C., Yan, W., Zu, X., Chen, M., Liu, L., Zhao, S., et al. (2014). Association between endothelial nitric oxide synthase $894 \mathrm{G}>\mathrm{T}$ polymorphism and prostate cancer risk: a meta-analysis of literature studies. Tumour Biol. 35, 11727-11733. doi: 10.1007/s13277-014-2097-4

Zhou, X. U., Qi, L., Tong, S., Cui, Y. U., Chen, J., Huang, T., et al. (2015). miR-128 downregulation promotes growth and metastasis of bladder cancer cells and involves VEGF-C upregulation. Oncol. Lett. 10, 3183-3190. doi: 10.3892/ol.2015.3689

Ziaei, S. A., Samzadeh, M., Jamaldini, S. H., Afshari, M., Haghdoost, A. A., and Hasanzad, M. (2013). Endothelial nitric oxide synthase Glu298Asp polymorphism as a risk factor for prostate cancer. Int. J. Biol. Markers 28, 43-48. doi: 10.5301/JBM.2012.9585

Zu, X., Tang, Z., Li, Y., Gao, N., Ding, J., and Qi, L. (2006). Vascular endothelial growth factor-C expression in bladder transitional cell cancer and its relationship to lymph node metastasis. BJU Int. 98, 1090-1093. doi: 10.1111/j.1464-410X.2006.06446.x

Conflict of Interest Statement: The authors declare that the research was conducted in the absence of any commercial or financial relationships that could be construed as a potential conflict of interest.

Copyright (C) 2018 Chen, Zhang, Cui, Liu, Qi, Li, Cheng, Ren, Li, Liu, Chen, Chen and $\mathrm{Zu}$. This is an open-access article distributed under the terms of the Creative Commons Attribution License (CC BY). The use, distribution or reproduction in other forums is permitted, provided the original author(s) and the copyright owner are credited and that the original publication in this journal is cited, in accordance with accepted academic practice. No use, distribution or reproduction is permitted which does not comply with these terms. 